Journal of Environmental Science and Public Health

doi: $10.26502 /$ jesph.96120052

fortune

Volume 3, Issue 1

Research Proposal

\title{
Biodiesel Production from Parkia Oil
}

\section{Sylvia Adipah*}

Department of Environmental Engineering and Science, Chongqing University, Chongqing, China

"Corresponding Author: Sylvia Adipah, Department of Environmental Engineering and Science, Chongqing University, Chongqing, China, E-mail: $\underline{\text { ransil351@yahoo.com }}$

Received: 12 December 2018; Accepted: 02 January 2019; Published: 08 February 2019

\section{Introduction}

At present, one of the ongoing challenges facing human society is to continue to provide energy in usable forms such as electricity while there is a growth in population and global warming are increasing. Under these circumstances, the utilization of renewable energy resources has become a global strategy for sustainable energy use, which is of particular importance for coping with increasing stress from the energy crises and global warming.

\subsection{Introduction of Parkia seed oil}

Parkia biglobosa is known as the African locust bean tree or néré, a perennial deciduous tree of the Fabaceae family that grows to between 7 and 20 meters high in some cases up to 30 meters [1]. It is found in Africa mostly, it contains a pod, sweet pulp and valuable seeds. Most of this locust seeds are used for medicinal purposes. It is grouped under spermatophytes, and vascular plants. The tree is a fire-resistant helophyte characterized by a thick dark gray-brown bark [2]. The pods of the tree are referred to as locust beans, can be seen as pink in the beginning and turn dark brown when fully mature. They are 30-40 centimeters long on average, with some reaching lengths of about 45 centimeters. Each pod can contain up to 30 seeds. The fermented seeds are used throughout Ghana and indeed the West Coast of Africa for seasoning, traditional foods [3].

Parkia species have found use traditionally as foods; medicinal agents are of high commercial value thus biogas production [4]. The fruit pulp of the species is eaten as food. The stem bark is employed in wound healing, while the wood is used for canoes and planking [5]. Ojewumi et al. [6] studied seeds of various species of Parkia have been investigated for protein and amino acid contents where sixteen amino acids were identified in Parkia biglobosa with 
the high level of glutamic acid. It was also reported that reported that the protein efficiency ratio, net protein retention, net protein utilization and true digestibility of Parkia biglobosa seeds were comparable to those of groundnuts and palm kernel seeds. The composition of the seed oil of P. biglandulosa has been earlier reported. It was found that the oil contains oleic acid (39.4\%), palmitic acid (8.8\%), stearic acid (13.3\%) and behenic acid (39.4\%) in an Indian variety. Human consumption and pharmaceutical consumption can cause shortage of oil production.

\subsection{Advantages of biogas energy}

- Biogas acts as a renewable source of energy.

- It produces less pollution.

- Sewage and waste products are the forms of raw material used.

- Biogas production does not require oxygen.

- Biomass energy maintain sustainable and clean environment due to usage of waste from landfill dump causing reduction of soil and water pollution.

- Biogas is relatively cheaper compared to other energy sources.

- Application of innovative technology helps in the production of electricity and heating purpose or as fuel for vehicle engine while it can be produced on small or large scale.

- Biogas can be produced from animal or human excreta, domestic and agriculture waste.

- It replaces chemical fertilizers by generating organic manure.

- It also leads improvement in sanitation and hygiene.

- It is a source for decentralized power generation.

- It creates employment in rural areas.

- Disposal of household wastes and bio-wastes are disposal in a healthy manner.

- The application of technology used is much simpler to operate.

- The effective technology of anaerobic digestion aids in inactivating pathogens and parasites leading to the reduction of waterborne diseases.

- Biogas decreases greenhouse effects on the atmosphere.

\subsection{Disadvantages of biogas energy}

- The value of biogas product is lower and it is an unattractive commercial activity.

- The yields lower dilute nature of substrates.

- The process is not economical on a large industrial scale.

- It is difficult enhance the efficiency of biogas systems.

- It also contains some gases like impurities which are corrosive to the metal parts of internal combustion engines.

- Biogas is not feasible to locate in all locations. 


\section{Research Questions}

- How will the technology help to generate sustainable energy?

- Is biogas production from Parkia Oil environmentally friendly?

- How do we improve the efficiency of the biogas production from Parkia oil?

- Is biogas production from parkia oil cost-effective compared to other technologies?

\section{Aim/Objective of the Research}

The objective of this study is to investigate the feasibility of using Parkia seed oil as a new potential non-edible feedstock for biodiesel production. The specific objectives of the study include;

- To synthesize four novel dicationic functional ionic liquids with an imidazolium structure for biodiesel production

- To investigate the catalytic performance of transesterification of Parkia seed oil with methanol to biodiesel

- To determine the effect of the optimization of reaction conditions on the transesterification using the response surface methodology (RSM)

- To evaluate the properties and application feasibility of the biodiesel obtained from Parkia seed oil.

- To use biogas production from parkia oil as an effective method to generate renewable energy.

\section{Significant of the Research}

With the shortening and increasing scarcity of known petroleum reserves which has made renewable energy sources more attractive and significant, the outcome of this study is to sell out Parkia seed oil and promote it cultivation. The study will also draw focus to other non-edible oil for biodiesel production. The study is also believed to bring enhancement and reduction of greenhouse gas emissions, regional development and social structure, especially to developing countries. The study is also fore saw to bring a balance between agriculture, economic development, and the environment. It is also expected that the methyl esters will help improve the lubrication properties of diesel fuel blend which will subsequently help reduce long term engine wear in diesel engines since biodiesel is said to be a good lubricant.

\section{Outcome of the Research}

Is to use Parkia seed oil to produce biogas energy with increasing stress from the energy crises.

\section{Expected Results}

The study is expected to cover the process of Parkia seed oil biodiesel production including synthesis of the catalyst, monitoring of the biodiesel production, the most enhanced method for the production of biodiesel and the efficient method for the biodiesel purification using. It is expected that the result of these studies will create the awareness and consequently enhance the cultivation and comprehensive use of Parkia seed oil. The study is expected to contribute knowledge to the scientific world. It is also expected that at least two or more publications will be obtained from the studies. 


\section{Materials}

Crude Parkia seed oil, Methanol, acetone, dichloromethane, N-methyl imidazole, acetonitrile, ethyl acetate, $\mathrm{NaOH}$, 1, 2-dibromoethane, 1, 3-dibromopropane, 1, 4-dibromobutane, 1, 5-dibromopentane, and 1, 6-dibromohexane will be used (grade of analytical reagent). Preparation of dicationic ionic liquids.

\subsection{Preparation of intermediates of $[\mathrm{m} I \mathrm{~m}] 2 \mathrm{CnBr} 2$}

Mixture of 1, 2-dibromoethane ( $0.02 \mathrm{~mol}, 3.75 \mathrm{~g})$ and dehydrated $\mathrm{N}$-methyl-imidazole $(0.04 \mathrm{~mol}, 3.284 \mathrm{~g})$ will be stirred with $50 \mathrm{~mL}$ acetonitrile solution in a three-neck flask at $70^{\circ} \mathrm{C}$ for $24 \mathrm{hrs}$. The mixture will be cooled to room temperature and filtered to give a crude solid. The crude solid will then be washed a number of times (3) with acetone and then vacuum-dried. By the same method, bis-(3-methyl-1-imidazole) -propylene dibromo-salt, bis-(3methyl-1-imidazole)-butylene dibromo-salt, bis-(3-methyl-1-imidazole)-pentylene dibromosalt, and bis-(3-methyl-1imidazole)-hexylene dibromic salt will be synthesized.

\subsection{Preparation of dicationic functional ionic liquids}

Bis-(3-methyl-1-imidazole)-ethylene dibromosalt ( $0.01 \mathrm{~mol}, 3.52 \mathrm{~g})$ and $\mathrm{NaOH}(0.02 \mathrm{~mol}, 0.8 \mathrm{~g})$ will be dissolved with $50 \mathrm{~mL}$ acetone solvent in a single-neck flask and stirred at room temperature for a day. The resulting precipitate of sodium bromide will be removed through filtration with the solvent allowed to evaporate under vacuum. The mixture will be washed repeatedly with dichloromethane, then evaporated under reduced pressure to yield the product (pale yellow powder bis-(3-methyl-1-imidazole)-ethylene dihydroxide,) expressed as IMC2OH. Via the same procedure, bis-(3-methyl-1-imidazole)-propylene dihydroxide, bis-(3-methyl-1-imidazole)-butylene dihydroxide, bis-(3-methyl-1-imidazole)-pentylene dihydroxide, and bis-(3-methyl-1-imidazole)-hexylene dihydroxide will be prepared (IMC3OH, IMC4OH, IMC5OH, and IMC6OH, respectively).

\subsection{Transesterification of crude Parkia seed oil}

The crude Parkia seed oil will be dehydrated at $140^{\circ} \mathrm{C}$ under vacuum in the rotary evaporator for 2 hrs. The dehydrated crude Parkia seed oil with a specified amount of dicationic functional ionic liquid catalyst will be mixed with excess methanol to form a homogenous reaction system in $100 \mathrm{~mL}$ three-neck flask and refluxed for some time at a recommended temperature under stirring with a constant speed. The ionic liquid catalyst will be available in the lower liquid phase. Mixture of methanol and glycerol will then be separated from the lower oily liquid phase by decantation. After draining off the glycerol, the upper mixture will be washed twice or more with 1:1 volume of water to remove excess methanol to achieve the target product.

\subsection{Alkali-catalyzed transesterification}

Methyl esters of Parkia seed oil will be prepared by refluxing the oil at a preset temperature with a certain volume of methanol containing the catalyst for $2 \mathrm{hrs}$ in a $250 \mathrm{~mL}$ three-neck reaction flask equipped with a condenser. After the reaction, the product will be purified by neutralizing with $10 \%$ of sulphuric acid. The product will then be washed and dried under reduced pressure at a temperature of about $70^{\circ} \mathrm{C}$ with a rotary evaporator. 


\section{Product Aanalyses and Yield Determination}

The methyl esters will be determined with GC-MS. This will be carried out on an Agilent HP-6890 gas chromatograph (Agilent Technologies, Palo Alto, CA, USA) with a HP-5MS 5\% phenylmethylsiloxane capillary column ( $30 \mathrm{~m} \times 0.25 \mathrm{~mm}$ i.e., film thickness $0.25 \mu \mathrm{m}$; Restek, Bellefonte, PA). The identification of fatty acids will be performed by comparing the obtained mass spectra with NIST05.LIB and NIST05s.LIB (National Institute of Standards and Technology) libraries data provided by the software (AMDIS-Chromatogram) of GC-MS system. Biodiesel yields will be determined with 7890A gas chromatograph (Agilent Technology Inc. USA) equipped with flame-ionization detector (FID) and HP-5 capillary column $(30 \mathrm{~m} \times 0.32 \mathrm{~mm} \times 0.25 \mu \mathrm{m})$. Biodiesel yield will be quantified using tetradecane as the internal standard. The analysis of biodiesel for each sample will carried out by dissolving $1 \mathrm{~mL}$ of the sample into $5 \mathrm{~mL}$ of $\mathrm{n}$-hexane and injecting $0.5 \mu \mathrm{L}$ into GC. The yield of the biodiesel will be determined using the following equation:

$$
\text { Biodiesel yield }=\frac{\mathcal{W}_{\text {tetradecane }} \times A_{B} \times f_{\text {tetradecane }}}{A_{\text {tetradecane }} \times \mathcal{W}_{s}} \times 100 \%
$$

Where $\mathrm{w}_{\text {tetradecane }}$ is the weight of the internal standard, $A_{B}$ is the peak area of methyl esters, $f_{\text {tetradecane }}$ is the response factor, $A_{\text {tetradecane }}$ is the peak area of the internal standard, and $w_{s}$ is the weight of the sample.

\section{Experimental Design and Statistical Analysis}

A three-variable and five-level central composite design (CCD) will be adopted and used in this study.

\subsection{Characterization of the biodiesel}

The major properties of the biodiesel will be evaluated using recommended standard methods. The properties include; cetane number, flash point, water content, acid value oxidative stability, copper corrosion, kinematic viscosity and sulfur content will be determined. Other properties including pour point, cloud point, cold filter plugging point, density at $20^{\circ} \mathrm{C}$, ash content and glycerin content will be determined.

\section{The Research Work and Progress of the Overall Arrangements/Research Plan}

The research will take a year to acquire reagents; to synthesize four novel dicationic functional ionic liquids with an imidazolium structure for biodiesel production; to investigate the catalytic performance of transesterification of Parkia seed oil with methanol to biodiesel to determine the effect of the optimization of reaction conditions on the transesterification using the response surface methodology (RSM) to evaluate the properties and application feasibility of the biodiesel obtained from Parkia seed oil; and submission of report.

\section{Feasibility Analysis}

This study is unique of its kind and is intended to bring/ establish that Parkia oil as one of the potential non-edible oils for biodiesel production. 


\section{Limitations}

Availability of high water usage concerning biogas production. High maintenance requirements will reduce the environmental benefits and increase carbon emissions and costs. Land use for Parkia tree will often compete with food crops, forest and urbanization. Food competition is ultimately the key social issue as energy crops will compete with food crops for valuable agricultural land. Taking waste wood from poor communities may remove selfsufficiency in areas where wood fuel is their only source of heat.

\section{Research Plan}

Chapter One: Introduction

i. Background of biogas production

ii. Global overview of biogas energy.

Chapter Two: Descriptive of Parkia seed oil.

Chapter Three: Methodology.

i. Preparation of Parkia seed oil for biodiesel production

ii. catalytic performance of transesterification of Parkia seed oil with methanol to biodiesel

iii. Effect of the optimization of reaction conditions on the transesterification using the response surface methodology (RSM)

iv. Evaluate the properties and application feasibility of the biodiesel obtained from Parkia seed oil.

Chapter Four: Assessment of energy generation from biogas.

i. Benefit analysis of biogas utilization

ii. Environmental impact assessment of using bioenergy

iii. Socio-economic impact of bioenergy production

Chapter Five: Conclusion and Recommendation.

\section{Description of Biogas production system}

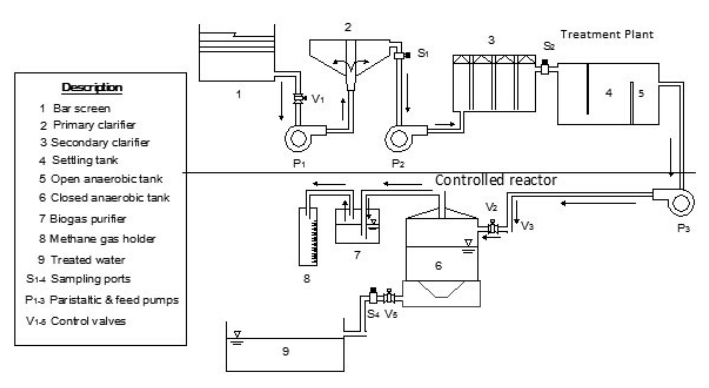

Figure 1: Biogas production system. 


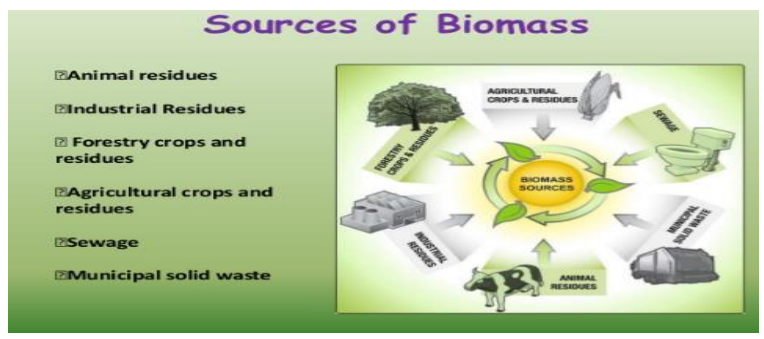

Figure 2: Sources of Biomass.

\section{Descriptive of Parkia biglobosa}

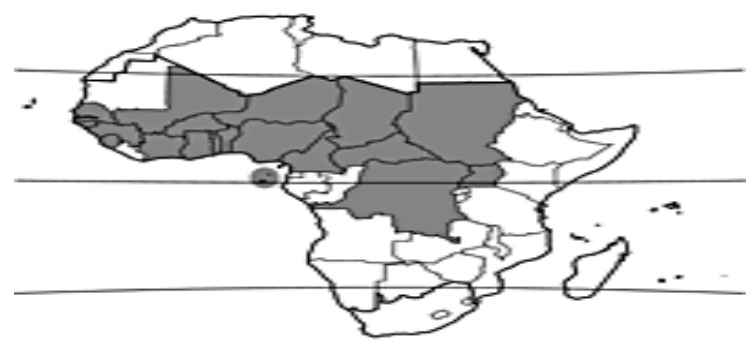

Figure 3: Parkia biglobosa can be found in the highlighted countries.

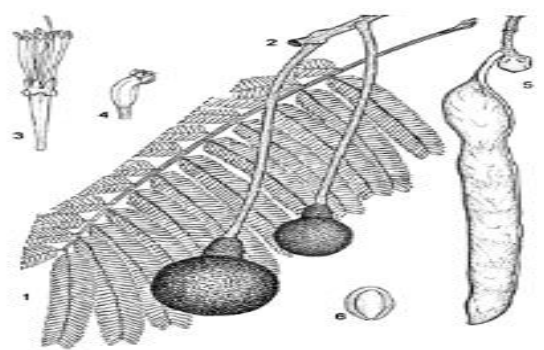

*1. Leaf; 2. branchlet with inflorescences; 3. bisexual flower; 4. male flower; 5. branchlet with fruit; 6. Seed.

Figure 4: The plant of Parkia biglobosa.

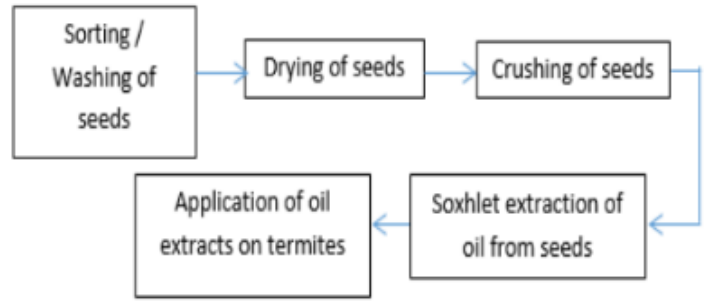

Figure 5: Flow chart for the extraction of oil from Parkia biglobosa. 


\section{Monitoring Procedures}

Performance figures, performance criteria and assessment aspects; biogas production biogas utilization environmental impacts socio-economic efficiency.

\section{Conclusion}

Biogas is yet to make significant impact in the energy sector in Ghana despite its potential for electricity, lighting (biogas lamps) and cooking in institutions, abattoirs and households. Biogas is a holistic approach to tackling energy crises in the twenty-first century. Professionals have proposed various ideas, plans, policies, and strategies and have implemented them in cities to achieve bioenergy goals. Government should play a role in promulgating supporting policies and strengthening the supervision and control of biogas projects. Emerging analysis is an appropriate method to evaluate the sustainability of alternative energy production, because it accounts for all inputs to the system. However, the generation of electricity does produce a product with higher energy quality and increased utility. Whether or not the conversion to electricity and the subsequent loss of sustainability is justified is a decision that needs to be made by the beneficiaries of the production system.

\section{Benefits from the Research Findings}

Communities, People, local governments and Researchers

\section{Resources Required}

Fund, Human resources, Research equipment, and Research facilities.

\section{Duration of the Research}

The research is made up of an experimental work and it will take a year for data collection and analyses.

\section{References}

1. Janick J. Parkia biglobosa African Locust Bean. The encyclopedia of fruit and nuts. Wallingford, U.K.: CABI North American Office (2008): 395-400.

2. Abioye E, Akinpelu D, Aiyegoro O, et al. Preliminary phytochemical screening and antibacterial properties of crude stem bark extracts and fractions of Parkia biglobosa (Jacq.). Molecules 18 (2013): 8459-8499.

3. Gernah DI, Inyang CU, Ezeora NL. Incubation and fermentation of African locust beans (Parkia biglobosa) in production of "dawadawa". Journal of Food Processing and Preservation 31 (2007): 227-239.

4. Ajaiyeoba EO. Phytochemical and antibacterial properties of Parkia biglobosa and Parkia bicolour leaf extracts. Afr J Biomed Res 5 (2002): 125-129.

5. Pouliot M, Bayala J, Raebild A. Testing the shade tolerance of selected crops under Parkia biglobosa (Jacq.) Benth. in an agroforestry parkland in Burkina Faso, West Africa. Agroforestry Systems 85 (2012): 477-488. 
6. Ojewumi ME, Omoleye AJ, Ajayi AA. The Effect of different starter cultures on the protein content infermented african locust beans. Inter J Eng Res and Technol 5 (2006): 249-255.

7. Ntui VO, Uyoh EA, Urua IS, et al. Regeneration of Parkia biglobosa Benth.: An important tree species of Africa. Journal of Microbiology and Biotechnology Research 2 (2012): 169-177.

8. Teklehaimanot Z. Exploiting the potential of indigenous agroforestry trees: Parkia biglobosa and Vitellaria paradoxa in sub-Saharan Africa. Agroforestry Systems 61 (2004): 207-220.

9. Uyovbisere EO, Elemo KA. Effect of tree foliage of locust bean (Parkia biglobosa) and neem (Azadirachta indica) on soil fertility and productivity of maize in a savanna alfisol. Nutrient Cycling in Agroecosystems, 62 (2002): 115-122.

Citation: Sylvia Adipah. Biodiesel Production from Parkia Oil. Journal of Environmental Science and Public Health 3 (2018): 113-121.

(C) This article is an open access article distributed under the terms and conditions of the
Creative Commons Attribution (CC-BY) license 4.0

